\title{
Clostridial Toxins in Strangulation Obstruction and Antibiotic-Related Colitis
}

\author{
Maria Allo, M.D. \\ Department of Surgery, University of Michigan Medical Center, Ann Arbor, Michigan 48109
}

Presented at the Annual Meeting of the Association for Academic Surgery, Great Gorge, New Jersey, November 11-14, 1979

\begin{abstract}
Clostridial toxins have previously been implicated in both strangulation obstruction and antibioticassociated colitis. These experiments show that these toxins are identical or similar in both diseases. Eighteen dogs with strangulation obstruction were studied. Closed midjejunal loops were constructed and bowel continuity was reestablished by end-to-end anastomosis. Venous blood supply to the closed loop was divided and ligated. Twelve dogs were sacrificed $18 \mathrm{hr}$ later when specimens of blood, loop fluid, and bowel wall were obtained for cultures; the remaining animals were sacrificed at $3 \mathrm{hr}$ and served as operative controls. Half of the dogs received $1 \mathrm{~g}$ of vancomycin 1 day before and $1 \mathrm{hr}$ before operation. Clostridia were isolated from the loop fluids in all but four of nine dogs that had received vancomycin. Bacteria-free loop fluids injected intracecally into hamsters caused diarrhea and colitis as did bacteria-free filtrates of Clostridium sordellii broth cultures isolated from the dogs. The animals pretreated with vancomycin showed ischemic changes in their obstructed bowel loops but their loop fluid was not toxic to hamsters. No vancomycin-treated animals had positive blood cultures, whereas six of nine non-vancomycin-treated dogs grew Clostridium spp. from their blood. These experiments show similarities between the toxins involved in these two diseases and suggest that modalities useful in identifying and treating antibiotic-associated colitis may be applicable to cases of strangulation obstruction.
\end{abstract}

\section{INTRODUCTION}

Previous studies of experimental strangulation obstruction, particularly work done by Bornside and Cohn [5-8] have implicated clostridial toxins as a lethal agent in loop fluids of strangulated intestine. Recently similar toxins have been shown to cause antibiotic-associated colitis in human patients and in hamsters $[3,15]$, and several laboratory tests have been developed to identify the presence of these toxins. In this study, clostridia were isolated from strangulated loops of dog intestine, and used to induce colitis in hamsters.

\section{MATERIALS AND METHODS}

\section{The Strangulation Obstruction Model}

Eighteen healthy mongrel dogs weighing $17-19 \mathrm{~kg}$ were anesthetized with secobarbital. Their intestines were divided at a site three-fourths of the distance from the ligament of Treitz to the cecum and $20 \mathrm{~cm}$ proxi- mal to that site as described by Bornside and Cohn [5]. Both ends of the segment were closed in two layers with interrupted 3-O silk sutures. The veins to the central $15 \mathrm{~cm}$ and the vessels at each end of this segment were divided and ligated. Continuity of the intestinal tract was restored by a two-layer end-to-end anastomosis and the abdomen was closed. All dogs received $500 \mathrm{cc}$ of $5 \%$ dextrose in normal saline solution intravenously. No other postoperative therapy was administered.

Six controls were operated upon and sacrificed $30 \mathrm{~min}$ later. Three of these animals received vancomycin, $1 \mathrm{~g}$ orally, 12 and $1 \mathrm{hr}$ before operation. The 12 remaining animals were sacrificed $18 \mathrm{hr}$ after operation and half of these animals received $1 \mathrm{~g}$ orally of vancomycin as described above.

Immediately after sacrifice, $100 \mathrm{cc}$ each of blood and loop fluid was removed by aspiration. Specimens of bowel wall from the obstructed segments were obtained for histol- 
ogy. Blood, loop fluid, and small bowel content before and after obstruction were cultured.

\section{Induction of Colitis}

Syrian hamsters (Charles River Laboratories, Newfield, N. J.) weighing $60-80 \mathrm{~g}$ were given either $0.3 \mathrm{cc}$ intraperitoneally or $3 \mathrm{cc}$ intracecally of either loop fluid from dogs with strangulation obstruction or cellfree broth cultures of clostridia. Three hamsters were used to test each specimen. Diarrhea was documented by fecal staining of paws and tail. Colitis was defined as dilatation and hemorrhage of the cecum with the histologic changes of colitis $[1,13]$. Necropsies were performed at the time of death or 3 days after injection, and cecal contents were prepared and tested for toxicity in both hamsters and cell cultures.

\section{Cell Culture Assay}

Monolayers of CV-1 monkey kidney cells or Walker cells were inoculated with 100 $\mu l$ of filtrates; a positive cytotoxic response consisted of rounding of $75 \%$ of cells within $24 \mathrm{hr}$ after inoculation.

\section{Isolation and Preparation of Broth Filtrates}

Samples of loop fluid were streaked onto prereduced laked sheep blood agar plates and phenylethyl alcohol agar (PEA) plates. At 48 and $72 \mathrm{hr}$ all organisms that looked suspicious for clostridia were subcultured anaerobically onto prereduced lake sheep blood agar. Identification was done biochemically with API strips, and by morphological criteria outlined in VPI manual [12]. In addition, organisms were grown in peptone yeast glucose (PYG) broth and further characterized by gas chromatography.

Cell-free broth cultures were prepared by growing the isolated organisms for $72 \mathrm{hr}$ in brain heart infusion broth. Cultures were then centrifuged at $10,000 \mathrm{~g}$ for $30 \mathrm{~min}$. Supernatants were sterilized by filtration through 0.45- $\mu \mathrm{m}$ Millipore filters (Millipore
Corp., Bedford, Mass.) and tested for toxicity in hamsters and in CV-1 monkey kidney cells and Walker cells as previously described above.

Toxic loop fluids and broth filtrates were neutralized by incubation for $30 \mathrm{~min}$ at room temperature with an equal volume of Clostridium sordellii antitoxin $(1 \mathrm{U} / 100 \mu \mathrm{l})(\mathrm{Bu}-$ reau of Biologics, Rockville, Md.), and tested for toxicity.

\section{RESULTS}

Cultures of small bowel content obtained prior to obstruction in animals not treated with vancomycin consisted of a mixed flora which included Bacteroides spp., Clostridium, Enterococcus, Peptostreptococcus, Escherichia coli, and occasionally other gram-negative bacilli. Dogs treated with vancomycin had markedly decreased numbers of culturable organisms. All of the dogs carried Clostridium perfringens as part of their flora and most carried at least two other species of clostridia. Predominant organisms in the loop fluids were $E$. coli and Clostridium spp. For purposes of this study attention was focused on the clostridia, and those isolated are summarized in Table 1.

Pretreatment with vancomycin rendered two of three 30 -min controls and two of six 18-hr obstructed dog intestinal loop fluids sterile for clostridia. The remaining animals had markedly reduced numbers of both organisms within species and numbers of clostridial species isolated per $100-$ cc loop fluid sample.

Blood cultures were obtained but they were not useful in defining any specific organism as dominant. In the six of nine dogs that had not received vancomycin, clostridia were isolated from the blood as were several other species.

Loop fluids from obstructed dogs that did not receive vancomycin caused lethargy, ataxia, and dcath $24-48 \mathrm{hr}$ after intraperitoneal injection into hamsters. This is similar to the effect seen when stool filtrates from animals dying with antibiotic-associated 
colitis are injected intraperitoneally into hamsters. When loop fluids were injected intracecally, lesions similar to those seen in hamsters given clindamycin, or intracecally injected stool filtrates from animals with antibiotic-associated colitis were observed 3 to 5 days following injection into four of six obstructed animals not treated with vancomycin. None of the hamsters treated with loop fluid from vancomycin-treated dogs, and none of the hamsters receiving loop fluid injections from 30 -min control dogs developed colitis. Intracecal injections of loop fluids from 8 of 12 animals obstructed for $18 \mathrm{hr}$ caused diarrhea in the injected hamsters. Two of these dogs had received vancomycin. Loop fluids of one of six control dogs obstructed for $30 \mathrm{~min}$ caused diarrhea in hamsters; this fluid came from a dog that had not received vancomycin.

When loop fluids were inoculated into cell cultures, 6 of 18 were weakly reactive. Only two of six fluids from dogs obstructed for $18 \mathrm{hr}$ which had received no antibiotics gave strongly positive results. Only one animal that had received vancomycin had even a weakly positive reaction. Only one of six controls had a weakly positive reaction. These data are summarized in Table 2.

The individual clostridial strains isolated were grown anaerobically at $35^{\circ} \mathrm{C}$ for $72 \mathrm{hr}$ in brain heart infusion broth, and injected intracecally and intraperitoneally into hamsters. These included four $C$. sordellii, three $C$. perfringens, four $C$. limosum, and one $C$. sporogenes. Three of four $C$. sordellii broths and one of three $C$. perfringens broths caused diarrhea in hamsters. Two of the three C. sordellii broths that caused diarrhea also caused colitis when injected intracecally. None of the other broths caused either diarrhea or colitis. These data are shown in Table 3. All four C. sordellii broths caused death when injected intraperitoneally into hamsters.

When the $C$. sordellii broth cultures were incubated with $C$. sordellii antitoxin their toxicity for hamsters injected either intraperitoneally or intracecally was not found.
TABLE 1

Clostridia Isolated from Obstructed Dogs

\begin{tabular}{lrllc}
\hline No antibiotic (9 dogs) & & Vanomycin treated $(9$ dogs) \\
\cline { 1 - 1 } \cline { 5 - 5 } Organism & $\begin{array}{r}\text { No. of } \\
\text { isolates }\end{array}$ & & Organism & $\begin{array}{r}\text { No. of } \\
\text { isolates }\end{array}$ \\
\hline C. sordellii & 11 & & C. sordellii & 0 \\
C. perfringens & 7 & & C. perfringens & 6 \\
C. limosum & 4 & & C. limosum & 0 \\
C. sporogenes & 1 & & C. sporogenes & 1 \\
None & 0 & & None & 4 \\
Other spp. & $4^{a}$ & &
\end{tabular}

a One isolate each of $C$. cadavens, $C$. paraputrificum, $C$. innocuum, and $C$. sphenoides.

Neither $C$. perfringens nor horse serum altered the effects described above. When the cell culture broth from the single active $C$. perfringens was incubated with horse serum or antitoxin to $C$. sordellii, there was no discernible effect.

\section{DISCUSSION}

In the 1960s Bornside and Cohn performed an extensive series of experiments to elucidate the role of bacterial toxins in strangulation obstruction [5-8]. They observed that the toxic substances contained in the fluid of the strangulated dog and rabbit intestinal loops could be neutralized with $C$. sordellii antitoxin, and that mice passively immunized with $C$. sordellii antitoxin did not suffer the lethal effects of the "toxic substance" in the loop fluid. Based on these neutralization experiments, the toxic substance was assumed to be $C$. sordellii toxin. Subsequently we have learned that toxins of both $C$. sordellii and $C$. difficile are neutralized by $C$. sordellii antitoxin [2]. Although $C$. difficile is more frequently implicated as the etiologic agent in antibiotic-associated colitis, $C$. sordellii has been isolated from hamsters with antibiotic-associated colitis [13]. However, the cytotoxicity of these strains has been difficult to demonstrate in vitro by cell culture assay. Our laboratory has reported a toxigenic strain of $C$. sordellit that was cytotoxic 
TABLE 2

Results Using Loop Fluids

\begin{tabular}{clllll}
\hline & \multicolumn{2}{c}{ Obstructed $\times 30 \mathrm{~min}$} & & \multicolumn{2}{c}{ Obstructed $\times 18 \mathrm{hr}$} \\
\cline { 2 - 2 } $\begin{array}{c}\text { Type of } \\
\text { toxin assay }\end{array}$ & $\begin{array}{c}\text { No } \\
\text { antibiotic }\end{array}$ & Vancomycin & & $\begin{array}{c}\text { No } \\
\text { antibiotic }\end{array}$ & Vancomycin \\
\hline $0.3 \mathrm{cc} \mathrm{IP}$ to & & & & \\
hamsters & $2 / 3$ Alive & $3 / 3$ Alive & & $2 / 6$ Alive & $6 / 6$ Alive \\
$3 \mathrm{cc}$ intracecally & $0 / 3$ Colitis & $0 / 3$ Colitis & & $4 / 6$ Colitis & $0 / 6$ Colitis \\
to hamsters & $1 / 3$ Diarrhea & $0 / 3$ Diarrhea & & $6 / 6$ Diarrhea & $2 / 6$ Diarrhea \\
Cell cultures & $1 / 3(+)$ & $0 / 3(+)$ & & $6 / 6(+)$ & $1 / 6(+)$ \\
\hline
\end{tabular}

in CV-1 monkey kidney cell culture, but this was only one of six strains that had been previously demonstrated to be toxin producers [2]. The findings of even weakly cytotoxic $C$. sordellii strains in isolates from the dog intestinal loops is significant.

Histologic changes of colitis in the obstructed dog intestinal loops could not be recognized because of the large amount of mucosal hemorrhage and necrosis associated with the venous obstruction. In the dogs given vancomycin and the untreated 30 -min controls there were no specific changes pathognomonic for colitis. However, hamsters given toxic loop fluids did show typical changes both grossly and histologically as described previously $[3,15]$.

The dramatic effect of antibiotics in reducing the numbers of recoverable organisms in the bowel flora has been repeatedly demonstrated. Oral vancomycin has been found to be effective in the treatment of antibiotic-associated colitis [9, 14]. When given orally, it is poorly absorbed and is exercised in very high concentrations $(80-$
$12,000 \mu \mathrm{g} / \mathrm{g}$ ) in human feces[11]. There is no significant nephrotoxicity associated with oral administration, and it is bactericidal even at low concentrations. Many other antibiotics including metronidazole, penicillin, tetracycline, and chloramphenicol have been considered for treatment of antibiotic-associated colitis. However, there are real and theoretical disadvantages to their use, and little actual clinical experience with them in antibiotic-associated colitis [10].

The significance of $C$. sordellii as an etiologic agent in antibiotic-associated colitis, or as a toxic factor in strangulation obstruction in human patients has not been well defined. At this time there is strong evidence to suggest that several toxigenic clostridia, and perhaps some nonclostridial toxigenic bacteria may be important in both these diseases. Recently described methods for toxin testing and isolation of clostridia including those used in this study are useful and important in defining them as etiologic agents in these diseases. Batts' report of three cases of Staphylococcus aureus enterocolitis as-

TABLE 3

Effects of Filtrates from Broth Cultures of Clostridia

\begin{tabular}{lllll}
\hline \multirow{2}{*}{ Assay } & \multicolumn{4}{c}{ Source of filtrate } \\
\cline { 2 - 5 } & C. sordellii & C. perfringens & C. sporogenes & C. limosum \\
\hline $0.3 \mathrm{cc}$ injected IP & $4 / 4$ Died & $0 / 3$ Died & $0 / 1$ Died & $0 / 4$ Died \\
3 cc intracecally & 3/4 Diarrhea & $1 / 3$ Diarrhea & $0 / 1$ Diarrhea & $0 / 4$ Diarrhea \\
to hamsters & 2/4 Colitis & $0 / 3$ Colitis & $0 / 1$ Colitis & $0 / 4$ Colitis \\
\hline
\end{tabular}


sociated with antibiotic administration illustrates the utility of cell culture assays to rapidly distinguish clostridial toxins from other colitigenic enterotoxins [4].

These experiments have demonstrated that fluid contained in strangulated dog intestinal loops contain a toxin capable of causing diarrhea and colitis in hamsters, and that this toxin is probably made by $C$. sordellii. Further, diagnostic modalities useful in detecting toxin in patients and experimental animals with antibiotic-associated colitis are useful in testing toxicity of loop fluids. Finally, vancomycin which is useful in the treatment of antibiotic-associated colitis prevents toxic sequelae by greatly decreasing or eliminating clostridia in the obstructed bowel loops.

\section{REFERENCES}

1. Abrams, G. D., Allo, M., Rifkin, G. D., Fekety, R., and Silva, J. Mucosal damage due to Clostridium difficile toxin: Similarity to clindamycin-associated typhilitis (Abstract No. 133). In Program and Abstracts of the Eighteenth Interscience Conference on Antimicrobial Agents and Chemotherapy, Atlanta, Ga., 1978.

2. Allo, M., Silva, J., Fekety, F. R., Rifkin, G. D., and Waskin, $H$. Prevention of clindamycin-induced colitis in hamsters by Clostridium sordellii antitoxin. Gastroenterology 76(2): 351, 1979.

3. Bartlett, J. G., Chang, T.-W., Gurwith, M., Gorbach, S., and Onderdonk, A. L. Antibiotic-associated pseudomembranous colitis due to toxin-producing Clostridia. N. Engl. J. Med. 298: 531, 1978.

4. Batts, D. H., Silva, J., and Fekety, R. Staphylococcal enterocolitis (Abstract No. 181). In Program and Abstracts of the Nineteenth Interscience Conference on Antimicrobial Agents and Chemotherapy, Boston, Mass., 1979.

5. Bornside, R. H., Floyd, E., and Cohn, I., Jr. Clostridium sordellii toxin: Further studies of serial changes of intestinal contents. J. Surg. Res. 4(95): 233, 1964.

6. Bornside, G. H., and Cohn, I. Intestinal bacteriology of closed loop, strangulation obstruction in dogs. Gastroenterology 41: 245, 1961.

7. Bornside, G. H., and Cohn, I. Clostridial toxins in strangulation intestinal obstruction in the rabbit. Ann. Surg. 152: 330, 1960.

8. Bornside, G. H., Dresden, C. F., Floyd, C. E., and Cohn, I., Jr. Serial changes of intestinal contents in strangulation obstruction. IAMA 183: 538, 1963.

9. Browne, R. A., Fekety, R., Silva, J., Boyd, D., et al. The protective effect of vancomycin on clindamycin-induced colitis in hamsters. Johns Hopkins Med. J. 141: 183. 1977.

10. Fekety, R., Silva, J., Toshniwal, R., Allo, M., Armstrong, J., et al. Antibiotic-associated colitis: Effect of antibiotics on Clostridium difficile, and the disease in hamsters. Rev. Infect. Dis. 1(2): 386, 1979.

11. Geraci, J. E., Heilman, F. R., Nichols, D. R., Wellman, W. E., and Ross, G. T. Some laboratory and clinical experiences with a new antibiotic, vancomycin. Proc. Staff Meet. Mayo Clin. 31: 564, 1956.

12. Holdeman, L. V., and Moore, W. E. C. Anaerobe Laboratory Manual. Virginia Polytechnic Institute and State University, Blacksburg, Va., 1975.

13. Lusk, R. H., Fekety, R., Silva, J., et al. Clindamycin-induced enterocolitis in hamsters. J. Infect. Dis. 137: 464, 1978.

14. Modigliani, R., and Delchier, J. C. Vancomycin for antibiotic-induced colitis. Lancet 1: 97, 1978.

15. Rifkin, G. D., Fekety, R., and Silva, J. Antibioticinduced colitis: Implications of a toxin neutralized by Clostridum sordellii antitoxin. Lancet 2: 1103 , 1977. 